\title{
Morpho-functional analysis of the mastoid region of the extinct South American mustelid $\uparrow$ Stipanicicia pettorutii
}

\author{
Marcos D. Ercoli ${ }^{1,2}$ \\ ${ }^{1}$ División Mastozoología, Museo Argentino de Ciencias Naturales "Bernardino Rivadavia”, CONICET, Buenos \\ Aires C1405DJR, Argentina \\ ${ }^{2}$ Instituto de Ecorregiones Andinas (INECOA), Universidad Nacional de Jujuy, CONICET, Instituto de Geología y \\ Minería (IdGyM), Av. Bolivia 1661, Y4600GNE San Salvador de Jujuy, Jujuy, Argentina (Current address) \\ Email: marcosdarioercoli@hotmail.com
}

\begin{abstract}
The morphology of the mastoid region in predators is informative about the hunting strategies and capacity of carrying prey. The purpose of this research was to describe the mastoid region and reconstruct the associated musculature of ${ }^{\dagger}$ Stipanicicia pettorutii Reig, 1956, a Pleistocene weasel with a distinctive morphology compared to its living relatives, and to make inferences about its predatory abilities. Galictis, a living weasel closely related to Stipanicicia, as well as other carnivorans, were used as comparative models. The muscle insertions identified in Stipanicicia presented a similar or larger development than Galictis. The insertion area of the muscles obliquus capitis cranialis, longissimus capitis, sternocephalicus pars mastoidea and cleidocephalicus pars mastoidea were found to be markedly developed and in a lateralised position with respect to the atlanto-occipital joint in hyaenids and mustelids, and especially in Stipanicicia, suggesting powerful lateral flexion and rotation movements in the fossil. The larger degree of advancement of the mastoid process in mustelids, and secondary in felids, would allow a powerful ventral flexion of the head. Stipanicicia would have exhibited powerful lateral movements and retraction of the head and neck, over restricted extension movements and, therefore, would have been a weasel specialised in subjugating and carrying prey of a relatively large size.
\end{abstract}

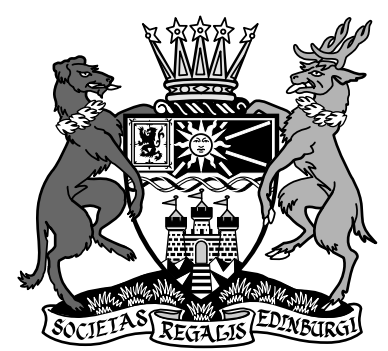

KEY WORDS: Carnivora, cervical musculature, cranial anatomy, killing behaviour, Mustelidae, palaeobiology, weasels.

Weasels from South America are represented by two lineages, musteline weasels (Subfamily Mustelinae) and lyncodontinine weasels (Subfamily Ictonychinae, Tribe Lyncodontini). Musteline weasels are represented by the species Mustela frenata, $M$. felipei and $M$. africana, which are distributed in the north of South America and, in the case of $M$. frenata, a great part of North America (Cabrera \& Yepes 1940; Emmons 1990). There are two genera and three species of lyncodontinines in South America: Lyncodon patagonicus, Galictis cuja and G. vittata; these last two are frequently called grisons.

South American mustelids were amongst the immigrant mammals of Holartic origin that arrived in South America during the Great American Biotic Interchange. The fossil record indicates that the first mustelids in the subcontinent were the lyncodontinine weasels, represented by $\dagger$ G. sorgentinii (Cione \& Tonni 2005; Woodburne et al. 2006; Sato et al. 2012; Soibelzon \& Prevosti 2012), recorded during the Vorohuean SALMA (South American Land Mammal Age) (3.0-2.4 My, Pliocene; Reig 1957; Cione \& Tonni 2005; Soibelzon \& Prevosti 2007). At the same time, related grison-like forms were present in the south of North America ${ }^{\dagger}$ Trigonictis cookii, ${ }^{\dagger} T$. macrodon, and ${ }^{\dagger}$ Sminthosinis bowleri; Reig 1957; Björk 1970; Kurtén \& Anderson 1980). The fossil record shows the presence of many more recent extinct species in South America assigned to the lyncodotinine genera Galictis, Lyncodon and Stipanicicia Reig, 1956 (see Rusconi 1932; Reig 1956; Pascual 1958; Berman 1994; Soibelzon \& Prevosti 2007, 2012), as well as fossil specimen representatives of extant species of lutrines, gulonines and musteline weasels (Reig 1956; Prevosti \& Soibelzon 2012; Sato et al. 2012; Soibelzon \& Prevosti 2012); the latter only known from a fossil material from the middle Holocene (Soibelzon \& Prevosti 2007).

Stipanicicia is the only genus of South American mustelids without a living representative. It presents features that show that it would have possessed a cervical osteo-muscular morphology unusual for lyncodontinine weasels. Stipanicicia pettorutii Reig, 1956 is known from cranial and mandibular remains that came, with doubts, from Marplatan deposits (Late PlioceneUpper Pleistocene) and confirmed Ensenadan deposits (MiddleUpper Pleistocene) from the General Alvarado, Pueyrredón and Necochea districts of the Buenos Aires province, Argentina (Reig 1956; Berman 1994; Prevosti 2000; Cione \& Tonni 2005; Prevosti \& Soibelzon 2012). This taxon was described by Reig (1956) as related to ictonychine extant forms from South America (Lyncodon and Galictis) and some fossil representatives from North America (e.g., ${ }^{\dagger}$ Trigonictis, ${ }^{\dagger}$ Lutravus) and the Old World (e.g., ${ }^{\dagger}$ Enhydrictis-Pannonictis lineage) (Furlong 1932; Gazin 1934; Reig 1956; Björk 1970).

In the original diagnosis of $S$. pettorutii (Reig 1956) and in the modified diagnosis provided by Berman (1994), it stood out due to several characteristics: a short and deep skull, with an elevated sagittal crest and a robust zygomatic arch (traits more similar to Lyncodon than Galictis); a conspicuous mastoid process; a noticeable postorbital constriction; a wide and long palate (even more than Lyncodon); a reduction of the dental formula (absence of P2, as in Lyncodon); and a superior carnassial with similar morphology to Galictis. Although the occipital area of the holotype specimen (MACN-Pv 14260) is partly 
damaged, and is totally absent in the hypodigm specimen (MLP 53-III-19-6), all of the mastoid processes and the lambdoid crests (except for details in their deepest aspect) are well preserved, allowing the main regions of insertion of the cervical musculature to be distinguished with relative clarity. Reig (1956) and Berman (1994) stated that S. pettorutii was a rodent-specialist carnivore, more similar to L. patagonicus than to G. cuja, and Prevosti (2000) suggested that the fossil species was more carnivorous than G. cuja. Beyond these scarce comments, and despite the distinctive morphology, until now there have been no palaeobiological studies of this taxon.

Mustelids are a very ecologically diverse group. In particular, the hunting behaviour varies widely between the different clades and species. Amongst the members of the family, the method by which prey is killed can occur in two basic ways, depending on the prey's size and aggressiveness, and the predator's specialisation: (a) the prey is pressed against the substrate while is bitten from above in the neck or the nape (and eventually in the posterior region of the neck, thorax and head; this strategy will be called from now on "bite down" strategy); or (b) fighting against prey by curling around it to make it stumble; this strategy often includes lateral rolls and biting the neck, frequently at the throat (this strategy will be called from now on "roll and curl" strategy). (Goethe 1964; Gossow 1970; Ewer 1973; Rowe-rowe 1978; Ben-David et al. 1991; Wilson \& Mittermeier 2009.)

The bite down strategy goes beyond weasels and is considered a widespread mustelid strategy, recorded in many mustelid lineages (ictonychines, mustelines, gulonines, helictidines and taxidiines; Ewer 1973; Riley 1985; Clark et al. 1987; Michener \& Iwaniuk 2001, and references therein). On the other hand, the roll and curl strategy is limited to only some specialised weasel lineages. The bite down strategy is used for hunting prey of a relatively small size and easy to dominate; the first bite is often imprecise and subsequently corrected (Dücker 1968; Gossow 1970; Heidt 1972; Ewer 1973). Taxa that typically perform this strategy are Galictis, Ictonyx striatus and Vormela (Dücker 1968; Rood 1970; Rowe-rowe 1978; Ben-David et al. 1991; Kays 1996; Wilson \& Mittermeier 2009; see below in this section). The roll and curl strategy allows the predator to avoid the prey's defences (e.g., kicking), although it implies a greater waste of energy and time spent on fighting, often leaving the predator exhausted. This technique is frequently used in cases in which the prey is an opponent of larger size and ferocity, and curling around it allows the predator to obtain a better position for precise bites. Generally, biting from above is only performed as a secondary strategy, or when the prey is dying at the end of the hunt. Taxa in which this more specialised strategy was documented include some species of Mustela (M. nigripes being the more extreme case) and Poecilogale (Rowe-rowe 1978; Vargas \& Anderson 1998; King \& Powell 2007; Wilson \& Mittermeier 2009), and it has been proposed tentatively for Lyncodon (through osteological postcranial comparisons; Ercoli 2015).

It is important to emphasise that these two hunting categories are a "coarse grain" simplification of weasel behaviour, and each species can perform either strategy depending on the circumstances or requirements (e.g., prey availability throughout the year; see Ewer 1973; Wilson \& Mittermeier 2009, and references therein). This is especially valid for weasels that have a more broad and opportunistic diet (e.g., M. vison; Ewer 1973; Wilson \& Mittermeier 2009). Variations of this kind have been well recorded in laboratory studies (e.g., Rowe-rowe 1978; Ben-David et al. 1991; Vargas \& Anderson 1998).

In general, hunting behaviour, and specifically the mustelids' killing bite, is more similar to that of felids than of dogs or hyaenids, although felids' vision and forelimbs have a more active participation, and the bites tend to be in the cervical region in small prey, or between the occipital zone and mostly in the throat and nasal area (suffocating them) in the case of prey of a larger size or with defence attitudes (Ewer 1973; Anyonge 1996; Karanth \& Sunquist 2000; Salesa et al. 2005; Meachen-Samuels \& Van Valkenburgh 2009). On the other hand, in canids and hyaenids, the prey is bitten repeatedly, or grabbed and shaken with the mandibles, which causes death by severe bleeding or multiple injuries, rather than from a specific bite (Ewer 1973; Radinsky 1981a; Ben-David et al. 1991; Anyonge 1996; Karanth \& Sunquist 2000).

For mustelids, the prey's death can occur due to suffocation in the case of bites in the trachea, puncture of vital organs, dislocation of the spine or destruction of the occipital zone (Rowe-rowe 1978; Vargas \& Anderson 1998; Ben-David et al. 1991). After the capture and death of the prey, weasels, as well as hyaenids and large felids in general (Spoor \& Badoux 1986; Karanth \& Sunquist 2000), often carry their prey to a safe place, which demands great physiological and musculoskeletal efforts (Cabrera \& Yepes 1940; King 1989; Zielinski 2000; King \& Powell 2007).

Ictonychine and musteline weasels share a great number of traits related to specialisations linked to hunting fossorial rodents (and in some cases lagomorphs and moles) by means of persecution into their burrows (Ewer 1973; King \& Powell 2007; Schutz \& Guralnick 2007; Wilson \& Mittermeier 2009). The diet of most weasels is hyper-carnivorous (Ewer 1973; King \& Powell 2007; Wilson \& Mittermeier 2009), which is reflected in the specialised dental morphology. In these taxa, the skull is short, the vision is reduced, the body is flexible and elongated and the limbs are short; features related to entering and moving quickly in rodents' burrows (Ewer 1973; Gambaryan 1974; Moritz et al. 2007; Horner \& Biknevicius 2010; see also Ercoli et al. 2013, 2015). Dominating, killing and carrying prey relies almost completely on the powerful neck and masticatory muscles of these taxa (Kaufmann \& Kaufmann 1965; Ewer 1973; Radinsky 1981a, b; King 1989; Zielinski 2000; King \& Powell 2007).

Although there exist numerous hunting behavioural studies for musteline weasels (e.g., Goethe 1964; Gossow 1970; Heidt 1972; Ewer 1973; Derting 1989; King 1989; Vargas \& Anderson 1998; King \& Powell 2007) and for ictonychinines (ictonychines from the Old World; e.g., Rowe-rowe 1978; Ben-David et al. 1991), less is known about lyncodontinines. In the case of Lyncodon patagonicus, the only record is anecdotal, and it was described as an aggressive, agile animal that enters into rodents' burrows (possibly Ctenomys and Microcavia species) (Koslowsky 1904; Cabrera \& Yepes 1940; Eisenberg 1989; Prevosti \& Pardiñas 2001; Prevosti et al. 2009; Schiaffini \& Prevosti 2013). It has been inferred as hyper-carnivorous on the basis of its dentition (Ewer 1973; Prevosti \& Pardiñas 2001; Schiaffini \& Prevosti 2013) and distinctly specialised in hunting in burrows on the basis of its postcranial anatomy (Ercoli 2015). Regarding Galictis species, both feed mainly on small vertebrates, including mice, cavies, frogs and a great variety of small animals. In some cases, their diets include a great proportion of lagomorphs and, in some cases, caviomorph rodents of a relatively large size (Cabrera \& Yepes 1940; Dalquest \& Harvey 1951; Eisenberg 1989; Sunquist et al. 1989; Kays 1996; Yensen \& Tarifa 2003a, b). The scarce descriptions suggest that both species frequently bite in the nape or head, or also in the back or neck, of their prey, even on large-sized caviomorphs (Dücker 1968; Rood 1970; Kays 1996; Gregg 2013). The hunting behaviour of G. vittata has been described in terms of biting the prey whilst pressing the neck, back or shoulder against the ground, then turning to bite the head (Dalquest \& Harvey 1951; Gregg 2013). In the case of G. cuja, 
Table 1 Specimens used for the osteological comparative analysis and mastoid musculature reconstruction of Stipanicicia pettorutii. In the case of fossil specimens, the reference literature is indicated in parentheses. For the living specimens, the sex, if known, is indicated in parentheses: $\mathrm{M}=$ male; $\mathrm{F}=$ female; ? = unknown.

\begin{tabular}{|c|c|}
\hline Species & Specimen \\
\hline \multicolumn{2}{|l|}{ Fossil ictonychines } \\
\hline Stipanicicia pettorutii & MACN-Pv 14260 (Reig 1956) \\
\hline Galictis sp. & MLP (Pv) 95-III-V-1 \\
\hline Lyncodon patagonicus & MLP (Pv) 96-V-1-1 (Prevosti \& Pardiñas 2001) \\
\hline Lyncodon bosei & MLP (Pv) 54-III-5-1 (Pascual 1958) \\
\hline Galictis cuja & $\begin{array}{l}\text { MACN-Ma } 13963 \text { (?); MACN-Ma 23291(?); MACN-Ma } 31.19 \text { (?); MACN-Ma } 25793 \text { (M); MACN-Ma } 29.795 \text { (?); } \\
\text { MACN-Ma } 13939 \text { (F); MLP 15.V.97.42 (F); MLP 8.V.59.6 (?); MLP 6.III.36.5 (M); MLP 2020 (M) }\end{array}$ \\
\hline Galictis vittata & FMNH 127293 (M); MACN-Ma 948 (F) \\
\hline Ictonyx libyca & FMNH 107197 (M); FMNH 107198 (F); MACN-Ma 24.12 (?) \\
\hline Ictonyx striatus & FMNH 177233 (F); FMNH 198372 (M) \\
\hline Lyncodon patagonicus & $\begin{array}{l}\text { MACN-Ma } 21980 \text { (M); MACN-Ma } 31.214 \text { (M); MLP 27-III-96-1 (?); MLP 6.III.36.32 (?); MLP (Pv) s/n (?); } \\
\text { MLP } 1255 \text { (?); MLP } 1256 \text { (?) }\end{array}$ \\
\hline Vormela peregusna & FMNH 103964 (M); FMNH 112448 (F); USNM 154995 (F) \\
\hline \multicolumn{2}{|l|}{ Living mustelines } \\
\hline Mustela erminea & FMNH 122020 (M); FMNH 122024 (F); FMNH 186328 (M); MACN-Ma 35.205 (M) \\
\hline Mustela eversmanni & FMNH 134578 (M); MACN-Ma 35.206 (?) \\
\hline Mustela nigripes & FMNH 25621 (M); FMNH 167200 (M); USNM 243990 (M); USNM 349716 (F) \\
\hline Mustela putorius & FMNH 140359 (F); FMNH 60690 (M); MACN-Ma 20645 (?); MACN-Ma 25.148 (?); USNM 174958 (M) \\
\hline Mustela vison & MACN-Ma 19.188 (F); MACN-Ma 19.185 (M); MACN-Ma 19.186 (M) \\
\hline \multicolumn{2}{|l|}{ Other living carnivorans } \\
\hline Crocuta crocuta & MACN-Ma 33.277 (?); MACN-Ma 6.12 (?) \\
\hline Canis familiaris & MACN-Ma 24.4 (?); MACN-Ma 4310 (?); MACN-Ma 24.29 (?); MACN-Ma 26.23 (?) \\
\hline Felis catus & MACN-Ma 33.27 (?); MACN-Ma 23700 (?); MACN-Ma 23917 (?) \\
\hline
\end{tabular}

the first bite may be in the lumbar area (Dücker 1968). Dücker (1968) commented that this species does not use the forelimbs at the beginning of the hunt, but it does use them when the prey is already subjugated. Grisons seem to be prone to bite down strategies, similar to the large Old World ictonychines.

Given that each hunting strategy involves different efforts and movements, especially in the cervical region, musculoskeletal variation in the mastoid region was expected. This present work puts forward the hypothesis that species which are typically bite down strategists would present traits that promote powerful ventral flexion of the neck movements; whilst the species specialised in using a roll and curl strategy would present traits that promote marked twisting and lateral efforts of the neck; movements that have been recorded in these hunting behaviours, respectively.

Similar hypotheses were tested in morpho-functional and palaeobiological studies of living and extinct felids (e.g., Antón et al. 2004; Salesa et al. 2005), but similar analyses in other carnivoran clades are still needed. On the basis of the previous comment, and in relation to the absence of previous studies focusing on the relationship between mastoid morphology and hunting strategy in weasels, the initial objective of this present study was the search for morpho-functional traits that allow the differentiation of weasels from other carnivore species, and the recognition of the different variations in hunting strategies within this family. The final objective of this research was to reconstruct the mastoid musculature and to inquire about the hunting habits of $S$. pettorutii.

\section{Materials and methods}

For the morpho-functional analysis of the mastoid region of $S$. pettorutii, the holotype (MACN-Pv 14260) was used as the main object of study, being the only known fossil specimen of the species that preserves that region. Cranial material of representative specimens from Mustelidae was used as comparative osteologic material. This material included all the ictonychine species: Galictis cuja, G. vittata, Ictonyx libyca, I. striatus, Lyncodon patagonicus, Poecilogale albinucha, Vormela peregusna; and five Mustela species (Table 1). Galictis cuja and M. putorius (species with a well-known myologic anatomy; Alix 1876; Barone \& Deutsch 1953; Gambaryan 1974; Evans \& Quoc An 1980; Ercoli 2015; Ercoli et al. 2013, 2015, 2016) were used as the main comparative mustelid models, and Crocuta crocuta, Canis familiaris and Felis catus as the nonmustelid models. Fossil specimens of the ictonychine species Galictis sp., L. bosei and L. patagonicus were also included in the sample (Table 1). All this material is housed at the mammalogical and palaeontological collections of the Museo Argentino de Ciencias Naturales (MACN) and the Museo de La Plata (MLP), Argentina; the Field Museum of Natural History, Chicago (FMNH); and the Smithsonian Institution, Washington, DC (USNM). The material from this last collection was photographed by Juliana Tarquini (MLP). Three-D models (high-resolution X-ray computed tomography) of $M$. frenata specimens from Digital Morphology (http://www. digimorph.org) and photographic material from a large number 
of Mustela species from the Animal Diversity Web (ADW) (http://animaldiversity.org; Myers et al. 2014) were also used as comparative models. The material studied corresponded to adult specimens (or eventually, young adults), identified on the basis of the complete dentition and the degree of fusion of cranial and long bone sutures.

First, detailed osteological descriptions and comparisons of the fossil material were made. For the myological reconstruction of S. pettorutii, descriptions and muscle maps of G. cuja were used as the main source for comparing insertion areas with the marks and other osteological features. The musculature of this species was analysed in detail by means of dissections carried out by the author and colleagues (Ercoli 2015; Ercoli et al. 2015, 2016). Muscular anatomy data sources available for other mustelid species (Cuvier \& Laurillard 1849; Alix 1876; Hall 1926; Williams 1955; Scapino 1968, 1974, 1987) and for carnivoran species mentioned as osteological comparative material (Cuvier \& Laurillard 1849; Reighard \& Jennings 1901; Barone 1967, 1976; Spoor \& Badoux 1986; Evans 1993; Antón et al. 2004; Evans \& de Lahunta 2013) were also used for the purpose of this research. The detailed comparison of the osteological material, and the muscle maps and descriptions, allowed the main insertion areas to be delineated.

Available bibliographic sources of general and specialised information were checked for the study of carnivores' hunting behaviour (Ewer 1973; Radinsky 1981a, b; Sunquist et al. 1989; Anyonge 1996; Karanth \& Sunquist 2000; Antón et al. 2004), in particular for ictonychine mustelids (Azara 1802; Cabrera \& Yepes 1940; Dalquest \& Harvey 1951; Kaufmann \& Kaufmann 1965; Dücker 1968; Rood 1970; Rowe-rowe 1978; Ben-David et al. 1991; Kays 1996; Gregg 2013), and for musteline mustelids (Hall 1951; Gossow 1970; Heidt 1972; Ewer 1973; Derting 1989; Vargas \& Anderson 1998; Zielinski 2000; King \& Powell 2007). Under a morpho-functional approach, this information was used to interpret how the different mastoid musculoskeletal configurations allow the performance of the different movements required for the hunting strategies of each lineage and, then, used to infer the hunting strategy of $S$. pettorutii.

\section{Results}

\subsection{Comparative analysis of the mastoid region of Stipanicicia pettorutii}

Figure 1 illustrates the comparisons between the main species mentioned in this section. In weasels and mustelids in general, the ventral end of the mastoid process projects below the articular condyle to a higher degree than in canids; similar to hyaenids and felids. On the other hand, starting from canids and hyaenids, then on to felids and then mustelids, the distances from the mastoid process to the rotation centre of the

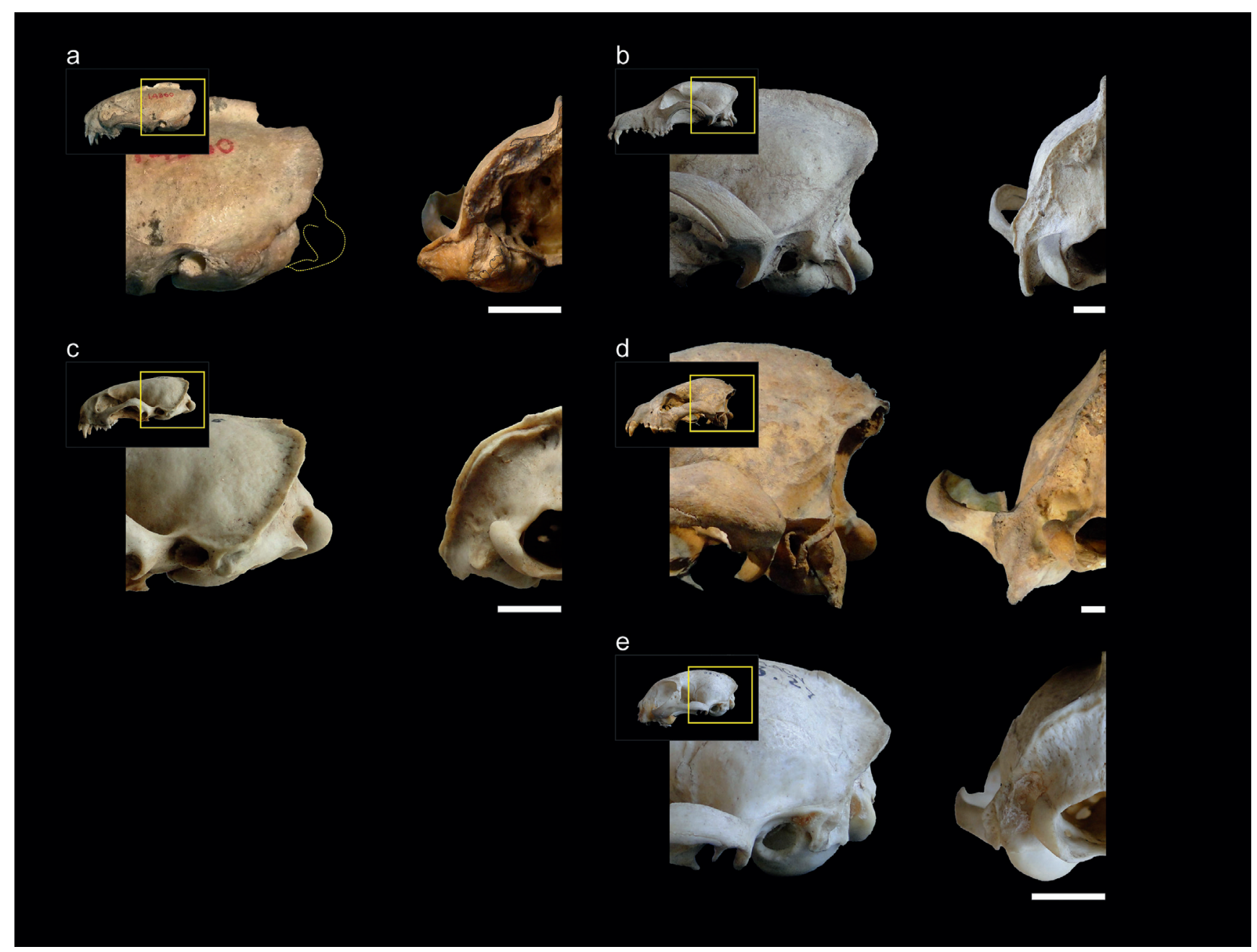

Figure 1 (a) Comparison between lateral (left) and occipital (right) views of the posterior sector of the skull of Stipanicicia pettorutii. (b-e) Representative members of the main carnivoran groups compared: (b) Canis familiaris (Canidae); (c) Galictis cuja (Mustelidae); (d) Crocuta crocuta (Hyaenidae); (e) Felis catus (Felidae). Scale bars $=10 \mathrm{~mm}$ 
atlas-cranium articulation, and the paraoccipital process, increase progressively in a cranio-ventral direction. Apart from this first general assessment, within weasels, there is a large variation in the degree of advancement of the mastoid process. In $S$. pettorutii, in the lateral view of the cranium, this process is located mainly caudal and, to some degree, is distanced from the external auditory meatus and dorsal to the level of the temporo-mandibular joint. Amongst living weasels, a similar configuration is documented in Lyncodon and Poecilogale specimens and in many species of the genus Mustela (e.g., male specimens of $M$. nigripes). Furthermore, a marked advancement is recorded in other weasels such as Galictis and Vormela, as well as in other mustelid lineages, such as otters (subfamily Lutrinae). Regarding the Ictonyx species, they have an intermediate condition, whereby I. libyca tend to possess a condition similar to the former morphology, and I. striatus the latter.

In mustelids in general, the presence of a broad and robust mastoid process is typical (see also Riley 1985). In many representatives of this family, this process is larger than those of most of the other carnivorans analysed (e.g., Felis, Canis) and similar or somewhat larger when compared to hyaenids (but see also other ursids, procyonids; Davis 1964; Radinsky 1981a). Stipanicicia pettorutii stands out because of these traits even when compared to other weasels, with a mastoid process that is strongly developed and laterally projected, distancing itself from the cranial vault. The marked degree of lateral projection of the mastoid process was highlighted in the original description given by Reig (1956), who compared this condition to that observed in the fossil ictonychine ${ }^{\dagger}$ Enhydrictis. In Galictis, the degree of lateral projection of the mastoid process is similar to that observed in hyaenids, whilst in some species of Mustela (see also Radinsky 1981a, b), and in S. pettorutii, it is even larger. In $S$. pettorutii, the lambdoid crest protrudes, and is rough and thick, especially in its most ventral sector, similar to $P$. albinucha and some Mustela species such as M. nigripes, and greater than in living lyncodontinines. This crest is reduced in other ictonychines such as Ictonyx libyca and some specimens of Vormela peregusna.

In the occipital view of the skull, the dorsal projection of the mastoid process is low in weasels and lutrines in general, intermediate in small felids and relatively larger in hyaenids, canids, large mustelids and large felids (e.g., Antón et al. 2004; Salesa et al. 2005; Valenciano et al. 2013, 2015). The same pattern is observed when comparing the dorsal extension of the occipital region, which is elevated in hyaenids and canids. In weasels, the paraoccipital process's ventral projection is reduced - this structure is not preserved in S. pettorutii similar to small felids and to some felid extinct lineages (Antón et al. 2004; Salesa et al. 2005), contrary to what occurs in hyaenids and canids.

\subsection{Muscular reconstruction of Stipanicicia pettorutii}

Figure 2 illustrates the muscular maps reconstructed for $S$. pettorutii compared to G. cuja. In $S$. pettorutii, all the insertions of the muscles described for Mustelidae are recognised and present a large topological correspondence with that of G. cuja. The delimitation edges are marked to a similar degree to that present in male adult specimens of Galictis species. The greatest difference corresponds to the existence of an extra scar in $S$. pettorutii. This difference was highlighted by Ercoli (2015), proposing that this could be evidence of three bellies for the $m$. cleidocephalicus pars mastoidea (instead of the two recorded for G. cuja) in the fossil species. Although this possibility cannot be discarded, the recent revision of a new specimen of the lyncodontinine $L$. patagonicus revealed the presence of an extra belly for the $m$. sternocephalicus pars mastoidea (m. sternomastoideus) (M. Ercoli pers. obs.), in a coincident position with one of the scars assigned in the fossil specimen to the cleidocephalic group (Fig. 2a, c, e). Considering these reasons, and for the purpose of this research, the scar was considered (with a high degree of confidence) as an extra insertion of the sternocephalic group, without changing the morpho-functional implication. All the insertion areas in the mastoid process of $S$. pettorutii possess a similar or larger development than their counterparts in other weasels in general, and in G. cuja in particular.

The $m$. cleidocephalicus pars mastoidea ( $m$. cleidomastoideus) typically originates in the clavicular intersection. The usual area of insertion for this muscle is the ventral sector of the mastoid process. In $S$. pettorutii, this area is markedly rugose. As in Galictis, the $m$. cleidocephalicus pars mastoidea of the fossil species seems to have been represented by multiple bundles in its insertion (a condition relatively atypical within Carnivora; but see Spoor \& Badoux 1986; Evans \& de Lahunta 2013), including at least one cranial belly, corresponding to an area markedly robust, and other caudal ones, with less defined edges and caudally adjacent with the $m$. obliquus capitis cranialis (Fig. 2a, c). In $S$. pettorutii, there is a hypertrophy of the surface of the muscle insertions, especially in a lateromedial direction, beyond the potential presence of a third belly (see below in this section).

The bellies of $m$. sternocephalicus usually originate in the craniodorsal region of the manubrium in carnivorans. In Galictis, the $m$. sternocephalicus differentiates into a belly that inserts onto the dorsal part of the lambdoid crest (pars occipitalis) and into two other bellies that insert along the mastoid crest (pars mastoidea, superficial or dorsal belly) and onto its ventral extreme (pars mastoidea, deep or ventral belly). Something similar was also described for other mustelids such as Taxidea taxus (Quaife 1978). On the basis of the marks observed along the lateral mastoid surface and lambdoid crest, the bellies observed in Galictis seem to have been present in $S$. pettorutii, with the difference that both mastoid bundles, especially the ventral one, would have been hypertrophied in the fossil species, given the robustness and roughness of the mastoid sector of the lambdoid crest. As was commented above, a third scar defined as a robust crest, which ventrally surrounds the cleidocephalic insertions and that is cranially contiguous with the insertion of the ventral belly of the $m$. sternocephalicus pars mastoidea, would represent the attachment of an extra ventral belly compared to the Galictis configuration, and would be more similar to the other lyncodontinine genus Lyncodon, providing more evidence for this muscle group's development.

The $m$. splenius capitis usually originates from the spinous process of the first thoracic vertebrae and the cervical raphe. This laminar muscle inserts onto the lambdoid crest, ventral to the $m$. sternocephalicus and it continues with the insertion of the $m$. longissimus capitis. Although the marks left by this muscle are only evident in some brief sectors of the mastoid region, making difficult to understand its total extension, its development in $S$. pettorutii seems to have been similar to the typical condition of other mustelids.

The $m$. longissimus capitis typically originates from the dorsal processes of the articulations of the cervical vertebrae and the first thoracic ones. In $S$. pettorutii, the insertion area of the $m$. longissimus capitis, onto the caudolateral aspect of the mastoid process, is well delimitated and outstanding. It differentiates from Galictis and other weasels in general (but not from other carnivorans; see section 3.1 ) because of a relatively elevated position of the insertion area, and a laterocaudal instead of a ventral orientation.

The $m$. obliquus capitis cranialis originates from the edge and ventral aspect of the wing of the atlas. It presents an independent and well developed ventral belly in G. cuja, which 
a

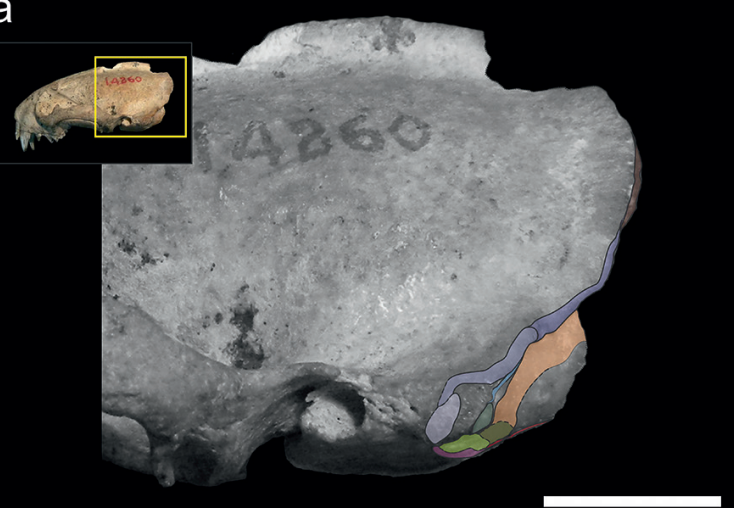

C
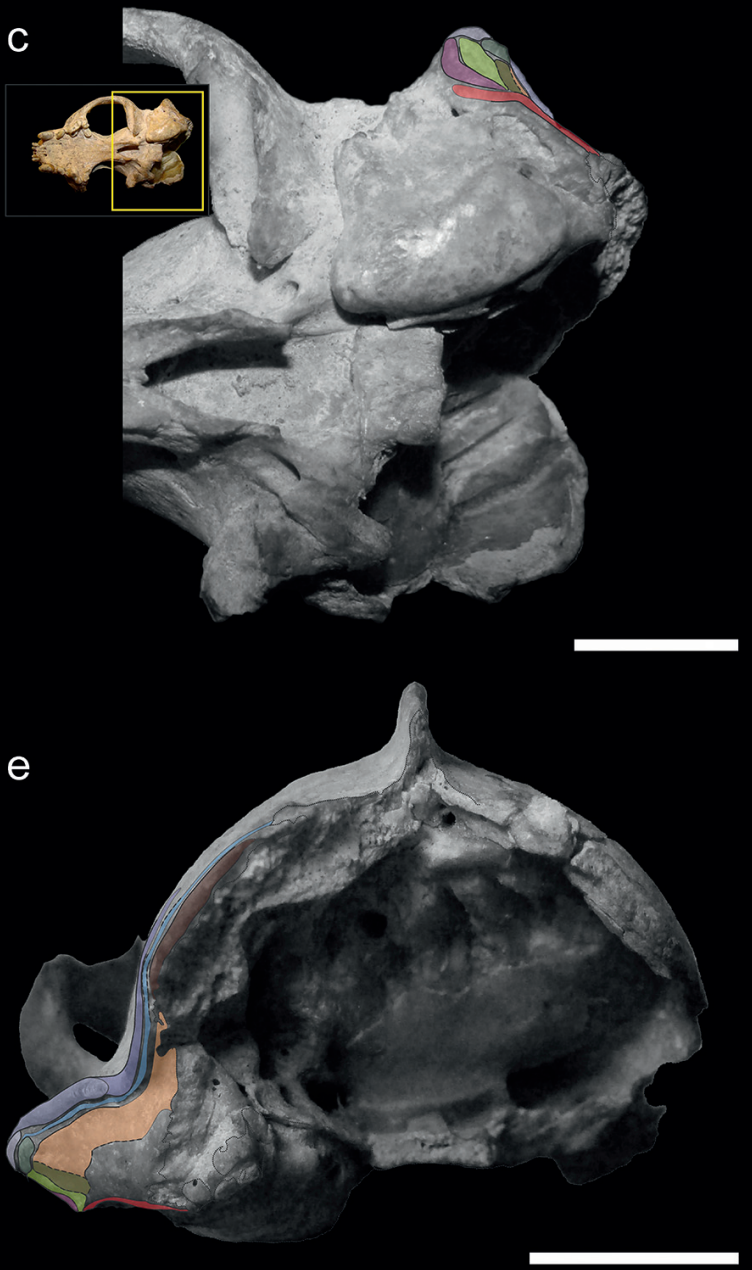

Rectus capitis lateralis

Obliquus capitis cranialis (dorsal)

Obliquus capitis cranialis (ventral)

Splenius capitis

Longissimus capitis b

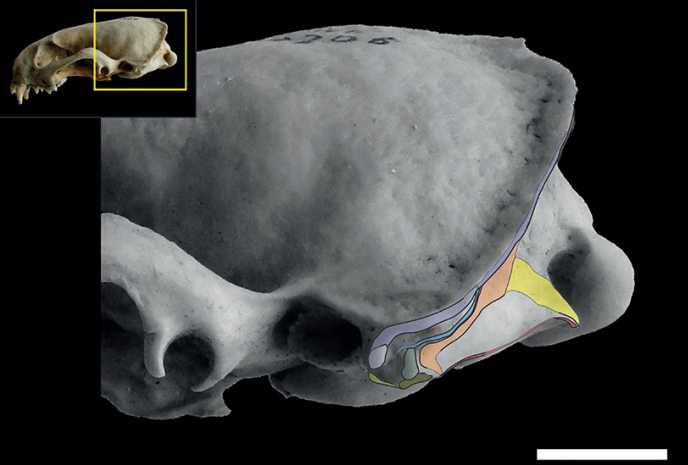

d

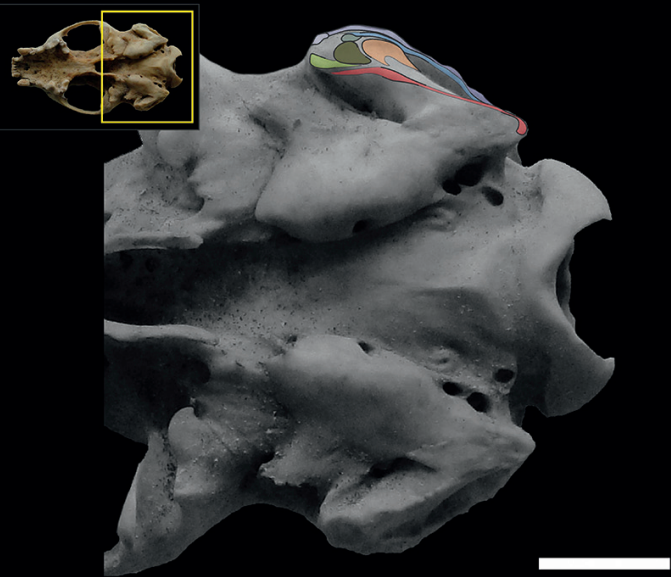

\section{f}

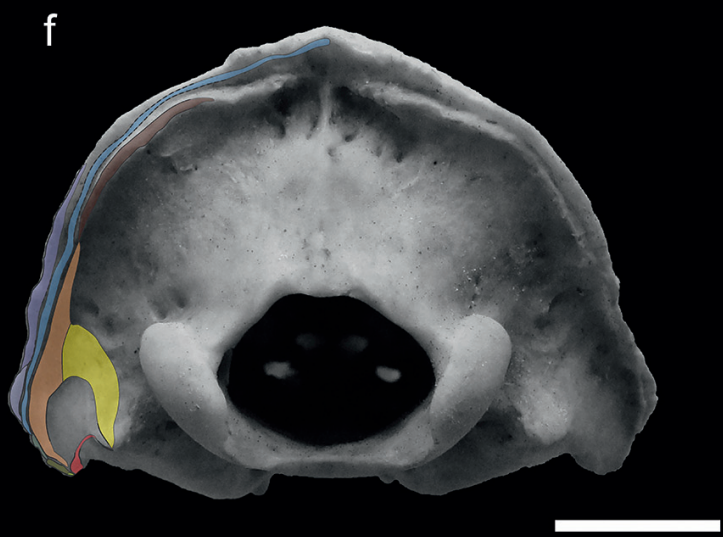

Sternocephalicus pars mastoidea (ventral)

Sternocephalicus pars mastoidea (dorsal)

Sternocephalicus pars mastoidea (ventral extra)

Sternocephalicus pars occipitalis

Cleidocephalicus pars mastoidea (craneal)

Cleidocephalicus pars mastoidea (caudal)

Figure 2 Reconstruction and comparison of mastoid musculature maps: (a, c, e) Stipanicicia pettorutii, skull in lateral (a), ventral (c) and occipital (e) views; (b, d, f) Galictis cuja, skull in lateral (b), ventral (d) and occipital (f) views. The thickness of the full lines indicate the confidence in the reconstruction of the margins of each area; the dashed lines indicate poorly defined or doubtful margins; and the dotted lines indicate damaged regions of the material. Scale bars $=10 \mathrm{~mm}$.

inserts onto the caudal aspect of the mastoid process and the ventral sector of the mastoid portion of the lambdoid crest (lateral to the $m$. rectus capitis lateralis). In $S$. pettorutii, the area of insertion of this belly is markedly extended, and the limit with the caudal belly of the $m$. cleidocephalicus pars mastoidea is hard to define. In S. pettorutii, a short crest protrudes caudally from the deep sector of the lambdoid crest at its maximum curvature, which may represent the insertion 
area of a dorsal belly of the $m$. obliquus capitis cranialis, as described for $G$. cuja (as seems to be the case for other caniforms, but with variants in its differentiation and insertion position; Cuvier \& Laurillard 1849; Fisher 1942; Williams 1955; Quaife 1978; Evans \& de Lahunta 2013; but see also Hall 1926, 1927), or at least the presence of fibres of the $m$. obliquus capitis cranialis extending broadly ventral to the lambdoid crest.

The origin area of the $m$. digastricus extends from the paraoccipital process to the ventromedial sector of the mastoid process in G. cuja (and mustelids in general; Hall 1926, 1927; Scapino 1987), and inserts onto the ventral edge of the horizontal ramus of the mandible. Although the origin marks are subtle and the paraoccipital process is broken in the fossil specimen, it is very probable that a similar configuration would have been present in S. pettorutii.

Because of the marked lateral projection of the mastoid process and the relatively caudal position of its apex in $S$. pettorutii as compared to $G$. cuja, the $m$. cleidocephalicus pars mastoidea, the $m$. sternocephalicus pars mastoidea and the ventral belly of the m. obliquus capitis cranialis present insertions markedly extended in a lateromedial direction. All these muscles, and the $m$. longissimus capitis, present their insertion centres relatively laterally, dorsally and caudally as compared to G. cuja. Although the insertion areas of other extensor muscles of the atlanto-occipital joint are damaged or absent in the fossil specimen (e.g., m. biventer cervicis; other bellies of $m$. rectus capitis and $m$. obliquus capitis), the total available area (represented by the lambdoid crest's height) in the occipital plane seems to have been poorly developed, similar to G. cuja and other living weasels.

\section{Discussion}

\subsection{Morpho-functional inferences on Stipanicicia pettorutii}

With the exception of the specimens of Stipanicicia pettorutii, South American fossil weasel remains belong to the living genera Galictis and Lyncodon (Berman 1994; Soibelzon \& Prevosti 2007; Prevosti \& Soibelzon 2012), and present similar mastoid morphology; therefore, major variations in hunting strategies were not expected. For example, the holotype of ${ }^{\dagger}$ L. bosei (MLP 54-III-5-1), as well as the fossil specimens of L. patagonicus (e.g., MLP 96-V-1-1), present mastoid and occipital morphologies very similar to those seen in female specimens of the extant species, with mastoid processes positioned caudally and relatively elevated in relation to the external auditory meatus, and with lambdoid crests reduced, especially in their middle sector. Hence, the mastoid morphology of $S$. pettorutii, clearly differentiable from the rest of the living and fossil lyncodontinines, is of particular interest. With the purpose of analysing the functional implications of the myological reconstruction of $S$. pettorutii, an evaluation was made of how the different muscular configurations recorded in the cervical region of each of the compared species are related to the motor functions required for their particular hunting strategies. Figures 2 and 3 illustrate the comparisons between the mastoid musculoskeletal configurations of the main species mentioned in this section.

When comparing the analysed carnivorans, one of the most remarkable features is the progressive advancement of the mastoid process, going from a backward position in canids and hyaenids, followed by small felids and many mustelids, including $S$. pettorutii, and coming to its maximum advancement in some ictonychines, such as Galictis and Vormela, and lutrines. This configuration modifies the insertion centres of the main mastoid muscles (e.g., m. sternocephalicus pars mastoidea, $m$. cleidocephalicus pars mastoidea and the ventral sector of $m$. obliquus capitis cranialis) to a relatively ventral and cranial position, distancing the mentioned centres from the atlanto-occipital rotation centre. These muscles are involved in the ventral and lateral flexion, fixing and retraction of the neck (Reighard \& Jennings 1901; Fisher et al. 2009; Evans \& de Lahunta 2013). The advancement of the mastoid process gives a greater mechanical advantage and range to the flexion movements of the head and neck, especially in laterally or ventrally flexed positions of the head. Such movements are crucial in hunting styles such as bite down in small felids and many mustelids, in which large forces must be applied to penetrate and crush the dorsal region of the prey. Antón et al. (2004, and references therein) and Salesa et al. (2005) arrived to a similar conclusion after comparing the mastoid morphology of living pantherines and machairodonts. These authors documented a relative advancement of the mastoid process in machairodonts, associating it with a greater importance of the ventral flexion of the neck and especially the atlanto-occipital joint (given by the $m$. obliquus capitis cranialis) in the killing bite strategy of this lineage. However, it is worth noting that some of the principal morpho-functional traits described by those authors as closely related to shear-bite sabre-tooth strategies in machairodonts (e.g., reduced paraoccipital process, great advancement of the mastoid process), are also present in living and extinct mustelids, in relation to similar function demands but in a different killing mode. The smaller cranioventral advancement of the mastoid process could be related to the reduced importance of the bite down strategy in $S$. pettorutii, some Mustela species, L. patagonicus, and P. albinucha, when compared to Galictis species and $V$. peregusna. The minimum advancement of the mastoid process in hyaenids and canids favours rapid movements instead of powerful ventral flexion, possibly in relation to stabilising and locating the head for the multiple bites and tugs required during their hunting strategies (Ewer 1973; Anyonge 1996; Karanth \& Sunquist 2000).

Regarding the development of the $m$. cleidocephalicus pars mastoidea, in hyaenids (Spoor \& Badoux 1986) and mustelids (Hall 1926, 1927; Williams 1955; Quaife 1978; Ercoli et al. 2015 ) it presents a broad insertion area, reaching a maximum degree in $S$. pettorutii. In canids and many felids, this muscle presents a relatively reduced insertion area and, in general, is restricted to the mastoid crest and does not reach the ventral sector of the mastoid process (Reighard \& Jennings 1901; Barone 1976; Antón et al. 2004; Salesa et al. 2005; Evans \& de Lahunta 2013), which give this muscle much less mechanical advantage for flexion. Felis catus seems to present an intermediate condition between these two groups (Reighard \& Jennings 1901), in which the muscle reaches the ventral end of the mastoid process in a reduced way. The reduced importance of the muscle in the ventral flexion is one of the greatest differences between extinct and living weasels and felids, and affects the configuration of the mastoid region (see diagrams from Quaife 1978; Antón et al. 2004; Salesa et al. 2005; Ercoli et al. 2015). The presence of multiple greatly developed cleidocephalic bellies and the advancement of their insertions (maximum in Galictis) suggest the great importance and precision of the ventral flexion movements in these mustelids, which is particularly important when the neck is already partially flexed.

On the lateral sector of the mastoid process, the insertion of the $m$. sternocephalicus pars mastoidea (which laterally and ventrally flexes the neck) is broadly developed in hyaenids, weasels and other mustelids (e.g., see diagrams from Quaife 1978 for Taxidea); and the same occurs for the m. longissimus 
a
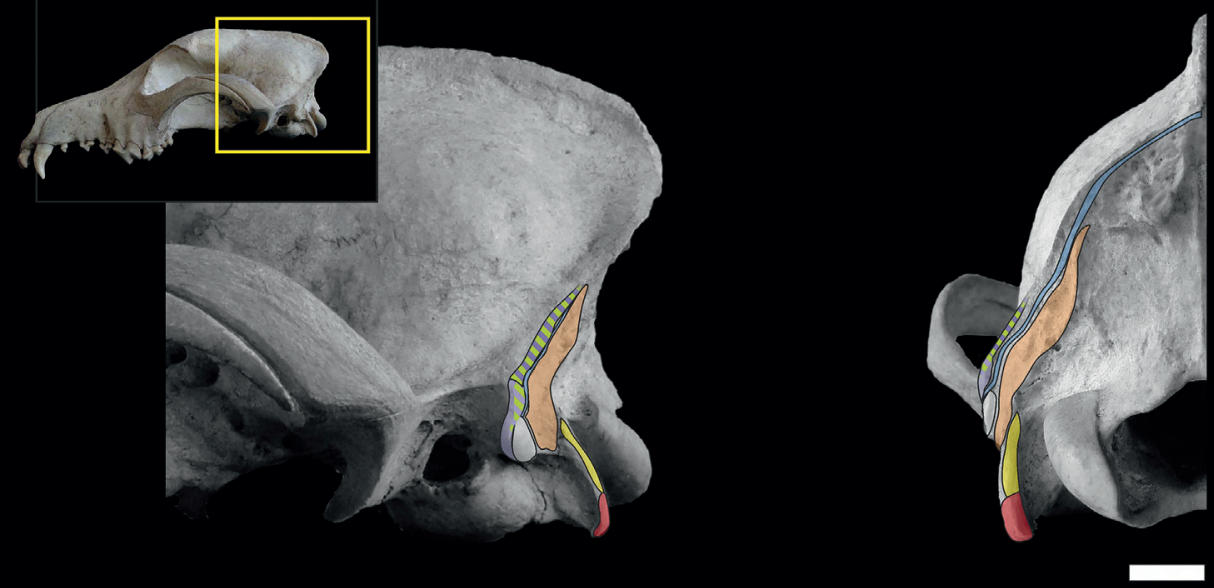

b
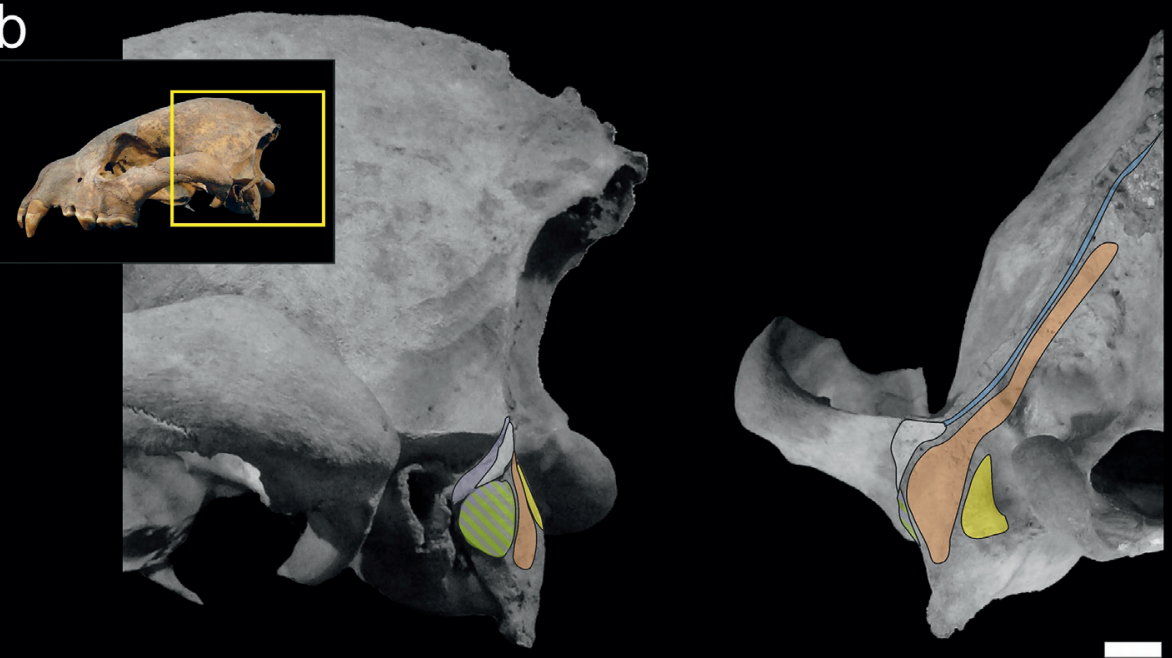

C
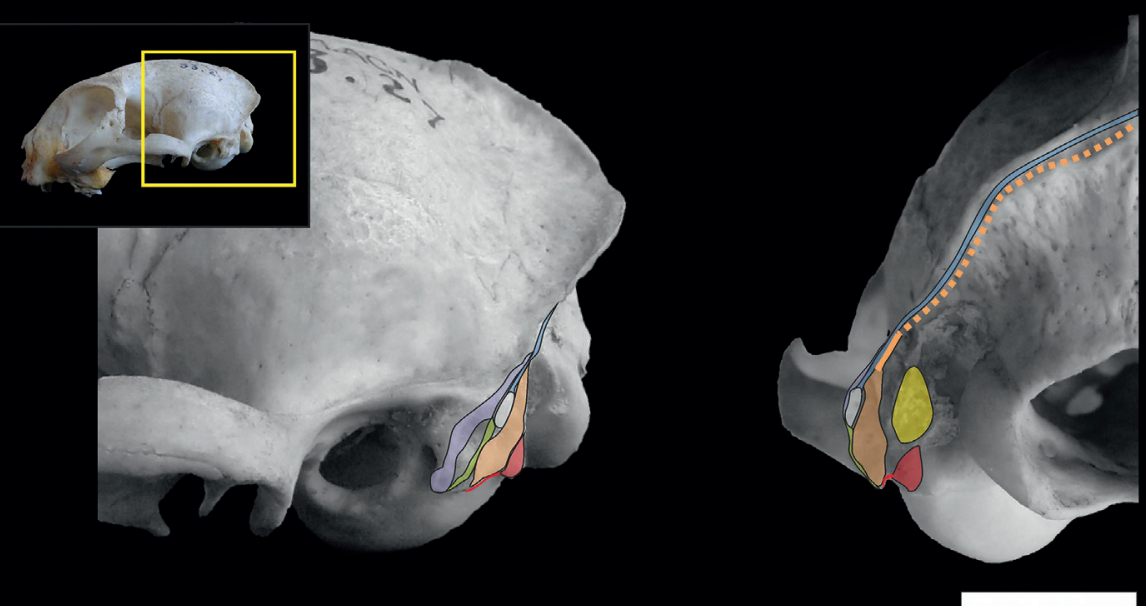

Figure 3 Muscular maps of the mastoid region (refer to Fig. 2 for the muscle key) of representative members of the carnivoran groups in lateral (left) and occipital (right) views of the skull: (a) Canis familiaris (Canidae); (b) Crocuta crocuta (Hyaenidae); (c) Felis catus (Felidae). Scale bars $=10 \mathrm{~mm}$.

capitis and the ventral sector of the $m$. splenius capitis (which extends and flexes the neck laterally; Reighard \& Jennings 1901; Quaife 1978; Spoor \& Badoux 1986; Antón et al. 2004; Evans \& de Lahunta 2013; Valenciano et al. 2013). In hyaenids, mustelids and, specifically, S. pettorutii, cervical muscles are provided with a large mechanical advantages and available insertion areas (Fig. 1), because of the lateral expansion of the mastoid process and the strengthened distal sector of 
the lambdoid crest (Quaife 1978; Radinsky 1981a). In these lineages, this configuration is accompanied by a relatively large mass and, eventually, additional bellies in the case of the sternocephalic group (Cuvier \& Laurillard 1849; Hall 1927; Quaife 1978; Spoor \& Badoux 1986; Ercoli 2015; Ercoli et al. 2016; and personal observations for L. patagonicus), which seems to have developed in an extreme degree in $S$. pettorutii.

The morphology of the mastoid process, and the positions and development of these muscles, are related to a large retraction capacity of the head towards the body (by bilateral contraction of muscles), as well as to powerful lateral and rotation movements of the neck (by unilateral contraction). These functions are progressively more important in canids, small felids, hyaenids and mustelids, and specifically in $S$. pettorutii, as an extreme case within the compared species. These features coincide with what is expected for a progressive increase of the efforts required for carrying prey (especially for hyaenids and mustelids), and the resistance of the forces generated during the domination of large-sized prey whilst being grabbed between the jaws. In the case of the fossil weasel, this seems to be concordant with a roll and curl strategy applied to large or powerful prey. In the case of felids, their retractile claws and more mobile and powerful forelimbs allow them to have larger control of their prey when grabbing it; explaining, at least in part, the lesser relative importance of some cervical muscular groups (Gorniak \& Gans 1980; Spoor \& Badoux 1986; Salesa et al. 2005; King \& Powell 2007).

In hyaenids, canids and large felids (Antón et al. 2004; but see also large mustelids, Valenciano et al. 2015), a marked elevation of the lambdoid crest is documented, which allows the elevation and extension of the insertion area for the obliquus capitis and rectus capitis muscular groups, increasing their mechanical advantage. In addition, a greater dorsal extension of the mastoid process is documented, which dorsally distances it from the level of the articular condyle (especially in canids), an area mainly occupied by the $m$. longissimus capitis and part of the m. sternocephalicus pars mastoidea; something that is also observed, to a lesser degree, in some large mustelids such as Taxidea taxus (Quaife 1978; see also Valenciano et al. 2013, 2015). In turn, the insertion area of the $m$. longissimus capitis is relatively broad in these lineages. All these features indicate an hypertrophied extensor muscle mass of the head, possibly in relation to allometric issues due to the relatively large size of these lineages (Hildebrand 1988), and also to the capacity of lifting large-sized prey in the case of the feliform lineages (Spoor \& Badoux 1986; Karanth \& Sunquist 2000). In weasels in general, the extension of the insertion area of the $m$. longissimus capitis is smaller, more similar to the one of small felids; lineages in which this muscle has been described as a lateral flexor, rather than an extensor of the neck (Reighard \& Jennings 1901). However, the advancement of the mastoid process in felids and mustelids, especially in Galictis, seems to explain, at least partially, the absence of an elevated position of insertion of the $m$. longissimus capitis in these lineages, given that this configuration keeps the action line of this muscle approximately at the same distance from the atlanto-occipital rotation centre in comparison with other carnivoran lineages. Given that the mastoid process is relatively backwards in $S$. pettorutii as compared to G. cuja, it would explain the relatively dorsal insertion position of the $m$. longissimus capitis in the fossil taxon, with no more than this biomechanical consideration.

The action of the $m$. obliquus capitis cranialis has been interpreted in quite variable ways in various anatomy researches, reflecting, amongst other things, the marked functional variations between the different lineages (e.g., extension, ventral flexion, axial rotation, lateral flexion, fixing; Davis 1964; Quaife 1978; Antón et al. 2004; Salesa et al. 2005; Evans \& de Lahunta 2013). In hyaenids, felids and weasels, many fibres of this muscle are located below the level of the articular condyle. In canids and larger mustelids (Quaife 1978; Valenciano et al. 2013, 2015), this muscle is located mainly above the articular level. In several carnivorans, including some mustelid and canid species, the most ventral portion differentiates from a dorsal portion ( $m$. obliquus capitis cranialis "dorsal" or "accessory"; Evans \& de Lahunta 2013; see also Cuvier \& Laurillard 1849: pl. 107; Fisher 1942; Ercoli 2015; Ercoli et al. 2016). On the basis of the reconstruction made for $S$. pettorutii, it is probable that this taxon possessed a condition for this trait very similar to the one present in living weasels, although, given the available area for the ventral portion of the $m$. obliquus capitis cranialis, this muscle would has been hypertrophied. This configuration indicates that for weasels, felids and hyaenids, the ventral portion of the m. obliquus capitis cranialis (independent or not) is employed, together with the $m$. rectus capitis lateralis, mainly for fixing the atlanto--occipital joint, for ventral flexion and, to a lesser degree, for lateral flexion movements (direction of movement partially restricted for the atlanto-occipital joint configuration; Evans \& de Lahunta 2013). On the other hand, given that the great ventral portion departs progressively ventrally from the rotation centre during flexion, the advancement of the mastoid process increases the participation of the muscle in the ventral flexion of the atlanto-occipital joint, as was observed in machairodonts by Antón et al. (2004); this also developed convergently in weasels. Conversely, the dorsal portion of the $m$. obliquus capitis cranialis participates in the antagonist extensor function. In the specific case of mustelids, the dorsal sector of this muscle probably acts efficiently as a rotator, in relation to the lateralised positions of its origin and insertion, and to the trajectory of the fibres with respect to the rotation centre (which acquire a great vertical component). Conversely, in canids, the entire $m$. obliquus capitis cranialis acts almost exclusively as an extensor, due to its elevated, but not markedly lateralised, insertion position (Evans \& de Lahunta 2013), in antagonism towards the $m$. rectus capitis lateralis and, secondarily, as fixer or rotator of the atlantooccipital articulation (Barone 1976; Antón et al. 2004); again indicating the greater importance of powerful extension in this lineage.

According to all that has been described, S. pettorutii would probably have had a differentiated dorsal portion of the $m$. obliquus capitis cranialis, in a similar position as in G. cuja and other weasels, with similar functional inferences. Furthermore, in the fossil specimen, the ventral belly of this muscle would have presented a greater lateromedial development, and lateral (but not ventral) positioning in comparison to G. cuja, exacerbating the importance of the muscle in fixing, retraction and lateral flexion movements, to an even greater degree than in hyaenids. However, the ventral extension of the muscle insertion area would have been similar in both taxa, without increasing the participation in ventral flexion (which is already important in mustelids) in the fossil taxon; or even less important in $S$. pettorutii, due to the relatively backward position of the muscle as compared to G. cuja.

The reduction of the paraoccipital process (the origin area of the $\mathrm{m}$. digastricus) in mustelids (as well as in $S$. pettorutii) and small felids (and also occuring in sabre-toothed extinct felids), could be related to variations in the range and strength of the mandible opening (Scapino 1987; Antón et al. 2004; Salesa et al. 2005). Apart from an allometric component in the development of this process (Scapino 1987), a short paraoccipital process and a craniocaudally elongated basicranium in mustelids favours the lengthening of the fibres of the $m$. digastricus, which allows a broad range of mandible opening when catching prey, compensating for the shortness of the mandible (Scapino 1987; Salesa et al. 2005). 


\subsection{Comments about the influence of size and sexual dimorphism}

Carnivorans in general, and weasels in particular, present evident allometric and sexual dimorphic differences that affect the muscular insertion areas (sagittal and lambdoid crests and, secondarily, the mastoid process); females have smaller body sizes and reduced muscular insertion processes as compared to males. Although a statistical study of the allometric effect would need a broader sample than the one used in this research, some observations concerning this topic are given below. King (1989) suggested that the small size of weasels facilitates the carrying of prey of a relatively larger size than themselves. Moreover, the smallest weasels are differentiated from the larger ones by the lower robustness of the muscular insertion areas; something to be expected due to the allometric relationship between the mechanical work and the muscular volume (Slijper 1946; Hildebrand 1988). This was also evident for the lyncodontinine fossil specimens analysed.

Previous researchers have investigated how the differentiation in body size between males and females affects hunting behaviour, as well as the size range and kind of potential prey (Moors 1980; Lynch \& Hayden 1995; but see Wiig 1986). The experimental studies of Rowe-rowe (1978) and Gossow (1970) demonstrated that, when gradually increasing the size of the prey offered to weasels, the females changed their hunting strategy at a relatively small prey size threshold, from bite down to roll and curl strategies, whilst males continued with the initial hunting behaviour, even when passing this threshold. Morphologically, females tend to have mastoid processes with a relatively more lateral direction and a more caudal position than males of the same species. These allometric changes (added to modifications in the development of the mass of the muscles involved; see Ercoli 2015; Ercoli et al. 2016) would aid in understanding how females can change to a roll and curl hunting behaviour more frequently, allowing them to prey upon large prey compared to their own body size, and similar to the ones preyed upon by males. Nevertheless, a great number of other ecological, ethological and physiological factors can influence the relative prey size and hunting strategy and success between males and females (e.g., females with offspring have to obtain prey more efficiently and quickly; males compete for the females in regards to their body size; and intraspecific competition). These factors are not totally understood (King \& Moors 1979; Moors 1980; King 1989, and references therein).

\subsection{Hunting strategies in weasels}

Amongst the model species compared, weasels are more similar to felids than to other carnivorans, because of the presence of an advanced and, to a greater or lesser degree, ventrally positioned mastoid process. This would relate to a similar hunting strategy of small prey that involves locating themselves over the prey and ventrally flexing the neck and head during the bite, killing the prey by biting the cervical region or crushing the occipital region (bite down or similar strategies). On the other hand, weasels also resemble hyaenids, to a greater extent than other carnivorans, because they possess a lateromedially extended mastoid region, which implies a broad development of the cervical musculature and powerful lateral flexion, rotation and retraction movements, which are important for the dragging of prey in both lineages; in addition to (particularly in weasels) the ability to hunt prey of a relatively large size by using roll and curl strategies.

The reduction of the dorsal extension of the mastoid region in weasels, as well as the entire occipital plane, is one of the main differences compared to large predators. As previously commented, this is due to multiple factors, including a relatively short muzzle, the absence of powerful extension movements during hunting or carrying of prey and, mainly, allometric issues related to the small body size.

From these comparisons, it can be recognised that there are osteological features related to the muscular reconfigurations that allow the behavioural extremes of the diversity of weasels' hunting strategies to be characterised. Species that frequently use the bite down strategy present ventrocranially-projected mastoid processes. This mastoid morphology allows these species to depress the head and neck quickly at the beginning, and then strongly, by means of the bilateral activation of the $m$. sternocephalicus pars mastoidea and the $m$. cleidocephalicus pars mastoidea, which increase their mechanical advantage by the progress of the ventral flexion of the head and neck. The ventral portion of the $m$. obliquus capitis cranialis is probably also recruited as the movement progresses, in already flexed positions. Other features that can be proposed as frequently associated with these species are: weak zygomatic arches; narrow palates; relatively elongated muzzles; and less specialised dentition (as well as some postcranial modifications; Ercoli 2015). These traits can be related to a broader diet, composed in general of relatively small prey, that requires fast bites instead of hard fighting (e.g., Dücker 1968; Heidt 1972; Ewer 1973; Rowe-rowe 1978; Ben-David et al.1991; see also Biknevicius \& Van Valkenburgh 1996; Meachen-Samuels \& Van Valkenburgh 2009; Goswami et al. 2011).

Species belonging to the roll and curl group are characterised by laterally projected mastoid processes, typically with its extreme located posterior to, and relatively separated from, the external auditory meatus (approaching the atlanto-occipital joint). Because of these modifications in this group, the lateral flexion, rotation and retraction of the head and neck are exacerbated (modifications that in turn decrease the mechanical advantage for ventral flexion, particularly for the $m$. obliquus capitis cranialis) and would allow these species to grab, generate and resist the prey's struggling movements during the fight, to destabilise the prey and to execute precise bites. Other features that characterise this group are the presence of: tall and wide zygomatic arches; wide palates; relatively short muzzles; robust canines; and more specialised hypercarnivorous dentition (Ewer 1973; Scapino 1987; Biknevicius \& Van Valkenburgh 1996; Meachen-Samuels \& Van Valkenburgh 2009; Goswami et al. 2011). All these features are present in S. pettorutii.

Although little is known about the behaviour of Lyncodon patagonicus (Cabrera \& Yepes 1940; Ewer 1973; Prevosti et al. 2009), it presents a cranial morphology compatible with that of the roll and curl small taxa (i.e., considering the lesser robustness of the mastoid process and other structures, due to allometric factors; Scapino 1987; Hildebrand 1988; MeachenSamuels \& Van Valkenburgh 2009, and references therein).

Once the prey is dead, weasels drag the corpse to a safe place (within the gallery system of the prey or to their own dens or shelters) before they start feeding (Dalquest \& Harvey 1951; Vargas \& Anderson 1998; King \& Powell 2007). The elongated neck allows them to carrying the prey forwards, which avoids it interfering with the movement of the forelimbs (but only up to a certain size of the prey; King \& Powell 2007), an activity carried out by the extensor muscles of the neck and head, attached to the lambdoid crest and occipital plate. Weasels drag larger prey by walking backwards when a prey size threshold is crossed (Rowe-rowe 1978; Vargas \& Anderson 1998), avoiding interference with the forelimbs. In this case, the carrying efforts rest on the retractor, fixer and lateral flexor muscles that are inserted in the mastoid region and the lateral region of the lambdoid crest. Weasels that prey upon relatively large-sized animals (typically roll and curl strategists, e.g., Poecilogale albinucha, Mustela nigripes) 
frequently utilise the backwards dragging method, requiring broader and more laterally projected mastoid processes than predators of small prey, in relation to an increase of the mechanical advantage for non-sagittal movements.

\subsection{Hunting strategy of Stipanicicia pettorutii}

This study is the first contribution to the knowledge of the hunting behaviour of $S$. pettorutii, and practically a unique analysis of the palaeobiology of the species (beyond some scarce comments about the diet; Reig 1956; Berman 1994; Prevosti 2000). The ability of this fossil species to make powerful ventral flexion movements, and the relative reduction of the strength of the extension movements of the head, seem to have been more similar to living weasels than to other carnivorans. S. pettorutii presents a cranial morphology more similar to roll and curl strategists that to the bite down ones, so it would have possessed the capacity to perform powerful lateral flexion, rotation and retraction of the head and neck. Most of the traits that distinguish S. pettorutii from the rest of the weasels (especially when compared to grisons) can be considered as an extreme case of the modifications required by roll and curl strategists, with a mastoid process so robust and exaggeratedly laterally projected that is only comparable with males of roll and curl strategists, which hunt relatively large prey (e.g., M. nigripes; Ben-David et al. 1991; Vargas \& Anderson 1998). On the other hand, the large mechanical advantage and the increased number of bellies of the mastoid muscles would have eventually allowed the taxon to perform powerful shaking movements of the head. In S. pettorutii, there are also other cranial traits frequently associated with this morphotype: robust zygomatic arch; muzzle and palatal proportions; and dental modifications related to hypercarnivory. Beyond the allometric differences, $S$. pettorutii would have presented greater morphological and, consequently, also behavioural similarities with L. patagonicus than with the Galictis species.

To sum up, $S$. pettorutii would have been a roll and curl predator, specialised for subjugating and carrying relatively large-sized prey, even when compared to the most specialised living weasels. It is likely that this taxon had been a predator specialising in burrower rodents (or other mammal species of similar habits) of considerable size, similar to living roll and curl strategists. In relation to this, there exist numerous species of rodents and rodent-like mammals found in Pleistocene deposits in the Atlantic coast of Buenos Aires province (Argentina) that could have been hunted by $S$. pettorutii (e.g., ${ }^{\dagger}$ Eucelophorus, ${ }^{\dagger}$ Paedotherium; Verzi 2002; Elissamburu 2004; Cione \& Tonni 2005; see also Elissamburu et al. 2011).

\section{Acknowledgements}

The author greatly acknowledges Dr. Francisco J. Prevosti, advisor for his $\mathrm{PhD}$ Thesis, from which this contribution emerged, for his advice and a review of an early version of this contribution. The author thanks Dr. Sergio F. Vizcaíno for his invitation to participate in this Special Issue; Lic. Juliana Tarquini for taking images of material housed in the USNM; and Agustina Dominguez and Dr. Alicia Álvarez for their help with the English grammar and style. The author thanks Mr. Sergio Lucero, Dr. David A. Flores, Ms. Stella Álvarez and Dr. Alejandro Kramarz (MACN), Dr. Marcelo Reguero, Dr. Itatí Olivares and Dr. Diego H. Verzi (MLP) and Dr. Bruce Patterson (FMNH) for granting access to material under their care. The author is very grateful for the comments and suggestions of two anonymous reviewers. This contribution was partially supported by the grant "Osvaldo Reig-2012" of SAREM, and PhD student grants of MACNCONICET and FCNyM-UNLP.

\section{References}

Alix, M. E. 1876. Memoire sur la myologie du putois (Putorius communis, Cuv.). Journal de Zoologie, Paris 5, 153-88.

Antón, M., Salesa, M. J., Pastor, J. F., Sanchez, I. M., Fraile, S. \& Morales, J. 2004. Implications of the mastoid anatomy of larger extant felids for the evolution and predatory behaviour of sabretoothed cats (Mammalia, Carnivora, Felidae). Zoological Journal of the Linnean Society 140, 207-21.

Anyonge, W. 1996. Microwear on canines and killing behavior in large carnivores: saber function in Smilodon fatalis. Journal of Mammalogy 77, 1059-67.

Azara, F. D. 1802. Apuntalamientos para la historia natural de los quadrúpedos del Paraguay y Río de la Plata. Madrid: La viuda de Ibarra.

Barone, R. 1967. La myologie du lion (Panthera leo). Mammalia 31, 459-514.

Barone, R. 1976. Anatomie, comparee des mammiteres domestiques. Paris: Vigot Freres Editeurs.

Barone, R. \& Deutsch, H. 1953. Myologie des membres du furet (Putorius furo). Bulletin de la Société des sciences vétérinaires et de médecine comparée de Lyon 55, 445-54.

Ben-David, M., Pellis, S. M. \& Pellis, V. C. 1991. Feeding habits and predatory behaviour in the marbled polecat (Vormela peregusna syriaca): and prey behaviour. Behaviour 118, 127-43.

Berman, W. D. 1994. Los carnívoros continentales (Mammalia, Carnivora) del Cenozoico en la provincia de Buenos Aires. PhD Thesis, Facultad de Ciencias Naturales y Museo, Universidad Nacional de La Plata, La Plata, Argentina.

Biknevicius, A. R. \& Van Valkenburgh, B. 1996. Design for killing: craniodental adaptations of predators. In Gittleman, J. (ed.) Carnivore behavior, ecology and evolution, Vol. 2, 393-428. Ithaca, New York: Cornell University Press.

Björk, P. R. 1970. The Carnivora of the Hagerman local fauna (late Pliocene) of southwestern Idaho. Transactions of the American Philosophical Society 60, 1-54.

Cabrera, A. \& Yepes, J. 1940. Mamiferos Sud-Americanos (vida, costumbres y descripción). Buenos Aires: Compañía Argentina de Editores.

Cione, A. L. \& Tonni, E. P. 2005. Bioestratigrafía basada en mamíferos del Cenozoico superior de la provincia de Buenos Aires, Argentina. Relatorio del XVI Congreso Geológico Argentino, Abstracts, 183-200.

Clark, T. W., Anderson, E., Douglas, C. \& Strickland, M. 1987 Martes americana. Mammalian Species 289, 1-8.

Cuvier, G. \& Laurillard, M. 1849. Recueil de Planches de Myologie. Paris: Dusacq.

Dalquest, W. W. \& Harvey, J. R. 1951. Behavior of young grisons in captivity. American Midland Naturalist 46, 359-66.

Davis, D. D. 1964. The giant panda: a morphological study of evolutionary mechanisms. Fieldiana: Zoology 3, 1-339.

Derting, T. L. 1989. Prey selection and foraging characteristics of least weasels (Mustela nivalis) in the laboratory. American Midland Naturalist 122, 394-400.

Dücker, V. G. 1968. Beobachtungen am kleinen grison, Galictis (Grisonella) cuja (Molina). Zeitschrift für Saugetierkunde 33, 28897.

Eisenberg, J. 1989. Mammals of the Neotropics, vol. 1. Chicago: The University of Chicago Press.

Elissamburu, A. 2004. Análisis morfométrico y morfofuncional del esqueleto apendicular de Paedotherium (Mammalia, Notoungulata). Ameghiniana 41, 363-80.

Elissamburu, A., Dondas, A. \& De Santis, L. 2011. Morfometría de las paleocuevas de la "Fm." Chapadmalal y su asignación a Actenomys (Rodentia), Paedotherium (Notoungulata) y otros mamíferos fósiles hospedantes. Mastozoología Neotropical 18, 22738.

Emmons, L. H. 1990. Neotropical rainforest mammals. Chicago: The University of Chicago Press.

Ercoli, M. D. 2015. Morfología del aparato músculo-esqueletario del postcráneo de los mustélidos (Carnivora, Mammalia) fósiles y vivientes de América del Sur: implicancias funcionales en un contexto filogenético. PhD Thesis, Facultad de Ciencias Naturales y Museo, Universidad Nacional de La Plata, La Plata, Argentina.

Ercoli, M. D., Echarri, S., Busker, F., Álvarez, A., Morales, M. M. \& Turazzini, G. F. 2013. The functional and phylogenetic implications of the myology of the lumbar region, tail, and hind limbs of the lesser grison (Galictis cuja). Journal of Mammalian Evolution 20, 309-36.

Ercoli, M. D., Álvarez, A., Stefanini, M. I., Busker, F. \& Morales, M. M. 2015. Muscular anatomy of the forelimbs of the lesser grison (Galictis cuja), and a functional and phylogenetic overview of 
Mustelidae and other Caniformia. Journal of Mammalian Evolution 22, 57-91.

Ercoli, M. D., Álvarez, A., Busker, F. Morales, M. M., Julik, E., Smith, H. F., Adrian, B., Barton, M., Bhagavatula, K., Poole, M., Shahsavan, M., Wechsler, R. \& Fisher, R. E. 2016. Myology of the Head, Neck and Thoracic Region of the Lesser Grison (Galictis cuja) in Comparison with the Red Panda (Ailurus fulgens) and Other Carnivorans: Phylogenetic and Functional Implications. Journal of Mammalian Evolution. Doi: 10.1007/s10914-016-9339-8.

Evans, H. E. 1993. Miller's anatomy of the dog. Philadelphia: W. B. Saunders Company.

Evans, H. E. \& de Lahunta, A. 2013. Miller's guide to the dissection of the dog. Philadelphia: W. B. Saunders Company.

Evans, H. E. \& Quoc An, N. 1980. Anatomy of the ferret. In Fox, J. G. (ed.) Biology and diseases of the ferret, 19-69. Baltimore: Williams \& Wilkins.

Ewer, R. F. 1973. The carnivores. New York: Cornell University Press. 500 pp.

Fisher, E. M. 1942. The osteology and myology of the California river otter. Stanford: Stanford University Press. $66 \mathrm{pp}$.

Fisher, R. E., Adrian, B., Barton, M., Holmgren, J. \& Tang, S. Y. 2009. The phylogeny of the red panda (Ailurus fulgens): evidence from the forelimb. Journal of Anatomy 215, 611-35.

Furlong, E. L. 1932. A new genus of otter from the Pliocene of the Northern Grait Basin Province. Contributions to palaeontology from Carnegie Institution of Washington 418, 93-103.

Gambaryan, P. P. 1974. How mammals run. Anatomical adaptations. New York: John Wiley \& Sons. 367 pp.

Gazin, C. L. 1934. Upper Pliocene mustelids from the Snake River Basin of Idaho. Journal of Mammalogy 15, 137-149.

Goethe, F. 1964. Das verhalten der musteliden. Handbook of Zoology Berlin 8, 1-80.

Gorniak, G. C. \& Gans, C. 1980. Quantitative assay of electromyograms during mastication in domestic cats (Felis catus). Journal of Morphology 163, 253-81.

Gossow, V. H. 1970. Vergleichende verhaltensstudien an marderartigen I. Über lautau Berungen und zum beuteurhalten. Zeitschrift fur Tierpsychologie 27, 405-80.

Goswami, A., Milne, N. \& Wroe, S. 2011. Biting through constraints: cranial morphology, disparity and convergence across living and fossil carnivorous mammals. Proceedings of the Royal Society, London B 278, 1831-39.

Gregg, M. 2013. Galictis vittata. Animal Diversity Web. Accessed May 23, 2014 at http://animaldiversity.ummz.umich.edu/accounts/ Galictis vittata/

Hall, E. R. 1926. The muscular anatomy of three mustelid mammals, Mephitis, Spilogale and Martes. University of California Publications in Zoology 30, 7-39.

Hall, E. R. 1927. The muscular anatomy of the American badger (Taxidea taxus). University of California Publications in Zoology 30, 205-19.

Hall, E. R. 1951. American weasels, vol. 4. Kansas: University of Kansas Publication, Museum of Natural History.

Heidt, G. A. 1972. Anatomical and behavioral aspects of killing and feeding by the least weasel, Mustela nivalis L. Arkansas Academy of Science Proceedings 26, 53-54.

Hildebrand, M. 1988. Analysis of vertebrate structure. New York: John Wiley \& Sons. xvi $+701 \mathrm{pp}$.

Horner, A. M. \& Biknevicius, A. R. 2010. A comparison of epigean and subterranean locomotion in the domestic ferret (Mustela putorius furo: Mustelidae: Carnivora). Zoology 113, 189-97.

Karanth, K. U. \& Sunquist, M. E. 2000. Behavioural correlates of predation by tiger (Panthera tigris), leopard (Panthera pardus) and dhole (Cuon alpinus) in Nagarahole, India. Journal of Zoology $\mathbf{2 5 0}$ 255-65.

Kaufmann, J. H. \& Kaufmann, A. 1965. Observations of the behaviour of tayras and grisons. Zeitschrift für Saugetierkunde 30, $146-55$.

Kays, R. W. 1996. Comments on the behaviour of grison (Galictis vittata) hunting an agouti (Dasyprocta punctata). Small Carnivore Conservation 15, 5 .

King, C. 1989. The advantages and disadvantages of small size to weasels, Mustela species. In Gittleman, J. L. (ed.) Carnivore behaviour, ecology, and evolution, vol. 1, 302-34. London: Chapman \& Hall. xiv +620 pp.

King, C. M. \& Moors, P. J. 1979. On co-existence, foraging strategy and the biogeography of weasels and stoats (Mustela nivalis and M. erminea) in Britain. Oecologia 39, 129-50.

King, C. M. \& Powell, R. A. 2007. The natural history of weasels and stoats. Oxford: Oxford University Press.

Koslowsky, J. 1904. Dos mamíferos de Patagonia cazados en el valle del Lago Blanco (territorio del Chubut). Revista del Museo de La Plata 11, 129-32.
Kurtén, B. \& Anderson, E. 1980. Pleistocene Mammals of North America. New York: Columbia University Press. 325 pp.

Lynch, J. M. \& Hayden, T. J. 1995. Genetic influences on cranial form: variation among ranch and feral American mink Mustela vison (Mammalia: Mustelidae). Biological Journal of the Linnean Society 55, 293-307.

Meachen-Samuels, J. \& Van Valkenburgh, B. 2009. Craniodental indicators of prey size preference in the Felidae. Biological Journal of the Linnean Society 96, 784-99.

Michener, G. R. \& Iwaniuk, A. N. 2001. Killing technique of North American badgers preying on Richardson's ground squirrels. Canadian Journal of Zoology 79, 2109-13.

Moors, P. J. 1980. Sexual dimorphism in the body size of mustelids (Carnivora): the roles of food habits and breeding systems. Oikos 34, 147-58.

Moritz, S., Fischer, M. S. \& Schilling, N. 2007. Three-dimensional fibre-type distribution in the paravertebral muscles of the domestic ferret (Mustela putorius $f$. furo) with relation to functional demands during locomotion. Zoology (Jena, Germany) 110, 197-211.

Myers, P., Espinosa, R., Parr, C. S., Jones, T., Hammond, G. S. \& Dewey, T. A. 2014. The Animal Diversity Web. Available at http://animaldiversity.org.

Pascual, R. 1958. "Lyncodon bosei" nueva especie del Ensenadense. Un antecesor del huroncito patagónico. Revista del Museo de La Plata 4, 1-38.

Prevosti, F. J. 2000. Un nuevo resto de $\dagger$ Stipanicicia pettorutii (Carnivora, Mustelidae) del Cuaternario de la provincia de Buenos Aires: implicancias bioestratigráficas. XV Jornadas Argentinas de Mastozoología, Resúmenes, 95.

Prevosti, F. J., Teta, P. \& Pardiñas, U. F. J. 2009. Distribution, natural history, and conservation of the Patagonian Weasel Lyncodon patagonicus. Small Carnivore Conservation 41, 29-34.

Prevosti, F. J. \& Pardiñas, U. F. J. 2001. Variaciones corológicas de Lyncodon patagonicus (Carnivora, Mustelidae) durante el Cuaternario. Mastozoología Neotropical 8, 21-39.

Prevosti, F. J. \& Soibelzon, L. H. 2012. Evolution of the South American carnivores (Mammalia: Carnivora). A paleontological perspective. In Patterson, B. D. \& Costa, L. P. (eds) Bones, clones, and biomes: an extended history of recent Neotropical mammals, 102-122. Chicago: The University of Chicago Press. $368 \mathrm{pp}$.

Quaife, L. R. 1978. The form and function of the North American badger (Taxidea taxus) in relation to its fossorial way of life. PhD Thesis, University of Calgary, Calgary.

Radinsky, L. B. 1981a. Evolution of skull shape in carnivores: 1. Representative modern carnivores. Biological Journal of the Linnean Society 15, 369-88.

Radinsky, L. B. 1981b. Evolution of skull shape in carnivores: 2. Additional modern carnivores. Biological Journal of the Linnean Society 16, 337-55

Reig, O. A. 1956. Note préliminaire sor un nouveau genre de mustélidés fossiles du pléistocene de la République Argentine. Mammalia 20, 223-30.

Reig, O. A. 1957. Un mustélido del género Galictis del Eocuartario de la provincia de Buenos Aires. Ameghiniana 1, 33-47.

Reighard, J. \& Jennings, H. S. 1901. Anatomy of the cat. New York: Henry Holt and Company.

Riley, M. A. 1985. An Analysis of Masticatory Form and Function in Three Mustelids (Martes americana, Lutra canadensis, Enhydra lutris). Journal of Mammalogy 66, 519-28.

Rood, J. P. 1970. Ecology and social behavior of the desert cavy (Microcavia australis). American Midland Naturalist 83, 415-54.

Rowe-rowe, D. T. 1978. Comparative prey capture and food studies of South African mustelines. Mammalia 42, 175-96.

Rusconi, C. 1932. Dos nuevas especies de Mustélidos del piso ensenadense. Anales de la Sociedad Científica Argentina 113, 42-45.

Salesa, M. J., Antón, M., Turner, A. \& Morales, J. 2005. Aspects of the functional morphology in the cranial and cervical skeleton of the sabre-toothed cat Paramachairodus ogygia (Kaup, 1832) (Felidae, Machairodontinae) from the Late Miocene of Spain: implications for the origins of the machairodont killing bite. Zoological Journal of the Linnean Society 144, 363-77.

Sato, J. J., Wolsan, M., Prevosti, F. J., D’Elía, G., Begg, C., Begg, K., Hosoda, T., Campbell, K. L. \& Suzuki, H. 2012. Evolutionary and biogeographic history of weasel-like carnivorans (Musteloidea). Molecular Phylogenetics and Evolution 63, 745-57.

Scapino, R. P. 1968. Biomechanics of feeding in Carnivora. $\mathrm{PhD}$ Thesis, University of Illinois, Illinois, USA

Scapino, R. P. 1974. Function of the masseter-pterygoid raphe in carnivores. Anatomischer Anzeiger, Jena 136, 430-46.

Scapino, R. P. 1987. Function of the digastric muscle in carnivores. Journal of Morphology 150, 843-860. 
Schiaffini, M. I. \& Prevosti, F. J. 2013. Trophic segregation of small carnivorans (Carnivora: Mustelidae and Mephitidae) from the Southern Cone of South America. Journal of Mammalian Evolution 21, 407-16.

Schutz, H. \& Guralnick, R. P. 2007. Postcranial element shape and function: assessing locomotor mode in extant and extinct mustelid carnivorans. Zoological Journal of the Linnean Society 150, 895 914.

Slijper, E. J. 1946. Comparative biologic-anatomical investigations on the vertebral column and spinal musculature of mammals. Verhandelingen der Koninklijke Nederlandsche Akademievan Wetenschappen, afd. Natuurkunde (Tweede Sectie) 42, 1-128.

Soibelzon, L. \& Prevosti, F. J. 2007. Los carnívoros (Carnivora, Mammalia) terrestres del Cuaternario de América del Sur. In Pons, G. X. \& Vicens, D. (eds) Geomorfologia Litoral $i$ Ouaternari. Homentage a D. Joan Cuerda Barceló. Monographie de la Societat d'Història Natural de les Balears 12, 5-12.

Soibelzon, L. \& Prevosti, F. J. 2012. Fossils of South American land carnivores (Carnivora, Mammalia). In Ruiz, M. \& Shostell, J. (eds) Molecular population genetics, evolutionary biology and biological conservation of Neotropical carnivores, 509-30. New York: Nova Science Publisher. 738 pp.

Spoor, C. F. \& Badoux, D. M. 1986. Descriptive and fuctional myology of the neck and forelimb of the striped hyena (Hyaena hyaena, L. 1758). Anatomischer Anzeiger 161, 375-87.

Sunquist, M. E., Sunquist, F. \& Daneke, D. 1989. Ecological separation in a Venezuelan IIanos carnivore community. In Redford, K. H. \& Eisenberg, J. F. (eds) Advances in Neotropical mammalogy, 197-232. Gainesville: Sandhill Crane Press. 614 pp.

Valenciano, A. L, Abella, J., Sanisidro, O., Álvarez-Sierra, M. A. \& Morales, J. 2013. Functional morphology of skull and mandibles of the Late Miocene giant mustelid Eomellivora piveteaui Ozansoy, 1965 from Cerro de los Batallones (Madrid, Spain). Anatomical Record 296 (Special Feature), 283-84.
Valenciano, A. L., Abella, J., Sanisidro, O, Hartstone-Rose, A. Álvarez-Sierra, M. Á. \& Morales, J. 2015. Complete description of the skull and mandible of the giant mustelid Eomellivora piveteaui Ozansoy, 1965 (Mammalia, Carnivora, Mustelidae), from Batallones (MN10), late Miocene (Madrid, Spain). Journal of Vertebrate Paleontology doi: 10.1080/02724634.2014.934570.

Vargas, A. \& Anderson, S. H. 1998. Ontogeny of black-footed ferret predatory behavior towards prairie dogs. Canadian Journal of Zoology 76, 1696-1704.

Verzi, D. H. 2002. Patrones de evolución morfológica en Ctenomyinae (Rodentia, Octodontidae). Mastozoología Neotropical 9, 309-28.

Wiig, Ø. 1986. Sexual dimorphism in the skull of minks Mustela vison, badgers Meles meles and otters Lutra lutra. Zoological Journal of the Linnean Society 87, 163-79.

Williams, R. C. 1955. The osteology and myology of the ranch mink (Mustela vison). PhD Thesis, Cornell University, New York.

Wilson, D. E. \& Mittermeier, R. A. 2009. Handbook of the mammals of the world, vol. 1: Carnivores. Barcelona: Lynx Editions.

Woodburne, M. O., Cione, A. L. \& Tonni, E. P. 2006. Central American provincialism and the Great American Biotic Interchange. In Carranza-Castañeda, O. \& Lindsay, E. H. (eds) Advances in Late Tertiary Vertebrate Paleontology in Mexico and the Great American Biotic Interchange, 73-101. Mexico DF: Universidad Nacional Autónoma de México, Instituto de Geología y Centro de Geociencias.

Yensen, E. \& Tarifa, T. 2003a. Galictis cuja. Mammalian Species $\mathbf{7 2 8}$ $1-8$.

Yensen, E. \& Tarifa, T. 2003b. Galictis vitatta. Mammalian Species 727, $1-8$

Zielinski, W. J. 2000.Weasels and Martens - Carnivores in Northern Latitudes. In Stenseth, N. (ed.) Activity patterns in small mammals, 95-118. Berlin: Springer-Verlag.

MS received 15 June 2015. Accepted for publication 2 October 2016. 
